\title{
Extended Beta-Lactamase (ESBL) Producing Salmonella typhi from Presumptive Typhoid Patients in Nasarawa State, Nigeria
}

\section{LAMINI Jebes Ngolo', NFONGEH Joseph Fur ${ }^{1}$, OROLE Olukayode Olugbenga}

\author{
${ }^{1}$ Department of Microbiology, Federal University Lafia, Nassarawa State, Nigeria
}

\section{ARTICLE INFO}

Article No.: 050918069

Type: Research

DOI: 10.15580/GJEPH.2018.3.050918069

Submitted: 09/05/2018

Accepted: 03/06/2018

Published: 15/06/2018

*Corresponding Author

Orole Olukayode

E-mail: orolekayode@yahoo.com

Keywords:

Prevalence, $\beta$-lactamase, Salmonella, antibiogram, resistance
This study was designed to determine the prevalence and antibiogram profile of extended spectrum $\beta$-lactamase producing Salmonella typhi from stool samples of symptomatic and asymptomatic typhoid patients from three selected hospitals in Nasarawa State, Nigeria. Four hundred and fifty stool samples were collected from hospitals in Doma, Lafia and Obi and isolation done using standard culture and serological techniques. Double disc diffusion technique was employed to determine isolates' capacity to produce $\beta$ lactamase and antibiogram profile carried out. Results showed that $\mathbf{7 6}(28.00 \%)$ of the samples collected were positive for Salmonella species. Prevalence of $S$. typhi in symptomatic patients was $13.77 \%$, while asymptomatic patients had $5.33 \%$, and a significant difference with a $p$ value of 0.129 obtained between symptomatic and asymptomatic patients. Prevalence of S. typhi in symptomatic patients with regard to sex showed that male patients were more susceptible to the isolates in Doma and Obi with values of $8(11.43 \%)$ and $11(15.28 \%)$ respectively, while female had $7(5.26 \%)$ and $7(5.60 \%)$ in Doma and Obi respectively. Patients aged between 18-29 years recorded $27(6.00 \%)$ prevalence rate as the highest, while age group 66 77 recorded $5(1.11 \%)$ prevalence throughout the duration of study. Isolates with the capacity of producing $\beta$-lactamase enzymes were $5(1.11 \%)$ in symptomatic patients and $1(0.22 \%)$ in asymptomatic patients. Antibiogram profile showed that ESBL-producers were sensitive to Augmentin and imipenem at $100 \%$, while non ESBL-producers were sensitive to Augmentin at $100 \%$, ceftriaxone at $85.86 \%$ and $100 \%$ resistant to imipenem and ampicillin. The study concluded that beta-lactamases with the capacity of conferring multidrug resistance were found in Salmonella typhi species isolated from willing patients in hospitals in Nasarawa State, Nigeria. 


\section{INTRODUCTION}

Salmonella species are obligate pathogens found all over the world causing mild to lethal infections, and contributing to economic cost losses in the form of therapy and treatment (Mark et al., 2017; Alocilja et al., 2003). Species Salmonella enterica typhi causing typhoid fever and others are described as being responsible for some food borne illnesses (Cardinale et al., 2009). High incidences of typhoid fever have been reported in enteric fever endemic areas with Salmonella enterica serovar typhi implicated as the main causal pathogen (Okonko et al., 2010; Parry, 2006).

Typhoid fever is treated using antibiotics, though resistance to different antibiotics have been variously reported in community and hospital environments. Resistant and continued spread of antibiotic resistant strains of bacteria and particularly Extended Spectrum Beta-lactamases (ESBLs) producing bacteria is now a global threat (Ranjbar, 2010; Naser 2009; Literacka et al., 2009). ESBLs are enzymes that attack and deactivate beta-lactam antibiotics (penicillins, cephalosporins, aztreonam and carbapenems). Increasing prevalence of resistant Salmonella typhi has been attributed to increasing use of antibiotics with the resultant prolonged therapy (Marathe et al., 2012), and resistance in ESBLs is due to the production of beta-lactamases which are plasmid mediated with the capacity of lateral transfer from bacteria to bacteria among the Enterobacteriaceae (Bradford, 2001).

Typoid fever disease is of public health importance affecting people of all walks of live in Nigeria and cases of outbreaks have been reported in some states including Nasarawa state. Disease burden due to typhoid fever is on the increase in some part of the world, while reductions have been recorded in some places (Marks et al., 2017; Crump et al., 2004). In Nigeria, due to lack of reliable epidemiological data it is difficult to ascertain the burden of illness though reports from studies in Kano, Niger, Lagos, Owerri, Abeokuta, and Jos in Nigeria had prevalence rates of $13 \%, 67.8 \%, 25.9 \%, 42 \%$, $80.1 \%$, and $42 \%$ respectively which were generally high (Adogo et al., 2015; Akinyemi et al., 2015; Ukaegbu,2014; Opara et al., 2014; Abdullahi et al., 2010; Okonko et al., 2010). The aim of this study was to evaluate the prevalence of Salmonella producing ESBLs strains by phenotypic methods and their profile of drug resistance amongst patients.

\section{MATERIALS AND METHODS}

\section{a Study area}

The study was carried out in three Hospitals in Obi, Doma, and Lafia, Nasarawa State. The major occupation of the people is farming, while others are civil servants and petty traders. While the hospitals in Obi and Doma are government general hospitals serving two local government council areas, Dalhatu Araf Specialist Hospital (DASH) in Lafia the state capital is a referral centre, and the most equipped government hospital in the state with different units and departments.

\section{Sample collection}

Sterile stool samples were collected as described by Cheesbough, (2010). Samples were collected twice weekly from September to November 2017. Inclusion and exclusion criteria was carried out by including all typhoid patients (symptomatic and asymptomatic) attending the hospitals and who willingly gave consent, while excluding those who declined to give consent.

\section{Isolation and identification of Salmonella}

Isolation of Salmonella species was carried out using selenite $\mathrm{F}$ enrichment broth and incubated at $35{ }^{\circ} \mathrm{C}$ for $10 \mathrm{~h}$ before reinoculation onto Salmonella-Shigella agars (SSA) at $35{ }^{\circ} \mathrm{C}$ for a day. Colonies (pink) with black centres (except $S$. paratyphi A, whose colonies do not have black centres) were subcultured to obtain pure isolates. Cultural characteristics and biochemical tests such as Gram staining, indole test, citrate utilization, catalase and urease tests, and MR-VP test (Methyl Red/Voges-Proskauer reaction) were carried out as described by Cheesbrough (2011) for the identification of the isolates.

\section{Serological identification of Salmonella typhi}

Serological identification of the isolates were as described by the methods of Guibourdenche et al. (2010). Serotyping was based on the agglutination of bacteria with specific sera to identify variants of the somatic (O) and flagella $(\mathrm{H})$ antigens.

\section{e Determination of multiple antibiotics} resistance (MAR) index

The MAR Index was determined using the modified methods of Krumperman (1983) and Paul et al. (1997). MAR is calculated from the result of the antibiotic susceptibility test thus; 
MAR Index $=\frac{\text { No. of antibiotics to which isolate is resistant }}{\text { Total }}$

\section{Detection of $\beta$-lactamase producing species of Salmonella typhi}

lodometric method of Catlin (1975) was used in the detection of $\beta$-lactamase producing species of Salmonella typhi. One hundred microliter of penicillin solution was dispensed into a well of microtitre plate, colonies of the suspected isolates were then emulsified into the solution. Two drops of starch was added, and incubated between 30-60 min after which 1 drop of iodine was added. Formation of blue solution that disappeared within $10 \mathrm{~min}$ showed the isolate was $\beta$ lactamase positive.

\section{g Phenotypic confirmatory test}

The modified methods of NCCLS (2002) was employed in the phenotypic confirmatory combination disc diffusion test. A disc of ceftazidime $(30 \mu \mathrm{g})$ alone and ceftazidime + clavulanic acid $(30 \mu \mathrm{g} / 10 \mu \mathrm{g})$ were placed at a distance of $25 \mathrm{~mm}$, center to center, on a MHA plate inoculated with a bacterial suspension of 0.5 McFarland turbidity standards and incubated overnight at $37{ }^{\circ} \mathrm{C}$. An increase in the inhibition zone diameter of 5 $\mathrm{mm}$ for a combination disc versus ceftazidime disc alone confirmed ESBL production.

\section{h Statistical analysis}

Statistical computation of data obtained were performed using Microsoft excel ${ }^{\mathrm{TM}} 2010$ and graph prism tab version 7.4 for analysis of Chisquare test and analysis of variance (ANOVA) to compare the results.

\section{RESULTS}

a

\section{Prevalence of Salmonella typhi in stool samples}

Out of the 450 stools sample collected and analysed (250 from symptomatic and 200 from asymptomatic patients) as shown in Table 1 , 76 samples were positive for Salmonella typhi at the prevalence rate of $16.89 \%$ (24.4\% for symptomatic and $7.50 \%$ for asymptomatic patients). There were no statistical difference at $p>0.05$ between the two groups.

Table 1: Prevalence of Salmonella typhi in stool samples of patients

\begin{tabular}{ccc}
\hline Sampling Period & $\begin{array}{c}\text { Symptomatic patients } \\
\mathbf{N}=\mathbf{2 5 0} \\
\mathbf{n = 6 1}\end{array}$ & $\begin{array}{c}\text { Asymptomatic } \\
\text { patients } \\
\mathbf{N = 2 0 0} \\
\mathbf{n = 1 5}\end{array}$ \\
\hline Week 1 & $8(13.11)$ & $2(13.13)$ \\
Week 2 & $4(6.19)$ & $1(6.67)$ \\
Week 3 & $9(14.75)$ & $4(26.67)$ \\
Week 4 & $7(11.48)$ & $0(0.00)$ \\
Week 5 & $6(8.84)$ & $3(20.00)$ \\
Week 6 & $10(16.39)$ & $2(13.13)$ \\
Week 7 & $9(14.75)$ & $1(6.67)$ \\
Week 8 & $8(13.11)$ & $2(13.13)$ \\
Total & $\mathbf{6 1 ( 2 4 . 4 \% )}$ & $\mathbf{1 5 ( 7 . 5 0 \% )}$ \\
\hline
\end{tabular}

\section{Prevalence of S. typhi in relation to different risk factors}

Prevalence according to gender showed that of the patients that were positive for the presence of $S$. typhi, 41 were males and 35 females as shown in Table 2. Male patients with S. typhi were $53.95 \%$, DASH 16(21.05\%), DOMA - 14(18.42\%) and OBI $11(14.47 \%)$, while the total prevalence in the female patient was $35(46.05 \%)$; DASH $21(27.63 \%)$, DOMA - $7(9.21 \%)$, and OBI $7(9.21 \%)$. According to the age groupings, the highest prevalence was within the age group 18 - 29 years, with 12,6 , and 4 symptomatic patients in DASH, OBI and DOMA respectively. The prevalence was low in the age group $54-77$ and $66-77$ years. There were no significant difference when compared with the prevalence of Salmonella typhi according to age group at $p>0.039$. A comparison of the prevalence rate based on the patients' occupation (Table 2) showed that students were the highest symptomatic patients with a prevalence of $20(32.78 \%)$, while farmers recorded the highest number of cases $6(40 \%)$ in asymptomatic patients. Civil servant had the lowest prevalence for both symptomatic and asymptomatic patients with $6(9.83 \%)$ and $1(6.66 \%)$ respectively. The prevalence values obtained according to the different occupations were significantly different at $p=0.129$. The study recorded 6 cases of ESBL-producers $5(8.19 \%)$ isolates were from symptomatic patients and $1(7.17 \%)$ from asymptomatic patient. Symptomatic patients with non ESBL producing Salmonella 
typhi obtained prevalence of 56(91.8\%), while $14(93.33 \%)$ prevalence was recorded from the asymptomatic patients as shown in Table 2.

Table 2: Prevalence of Salmonella typhi and ESBL-producers in patients

\begin{tabular}{|c|c|c|c|c|c|c|}
\hline \multirow{4}{*}{$\begin{array}{c}\text { Gender Prevalence (\%) } \\
\text { Sex } \\
\text { S. typhi in patients }\end{array}$} & \multicolumn{2}{|c|}{ DASH } & \multicolumn{2}{|c|}{ DOMA } & \multicolumn{2}{|c|}{ OBI } \\
\hline & & & & & & \\
\hline & Male & Female & Male & Female & Male & Female \\
\hline & $\begin{array}{c}16 \\
(8.33 \%)\end{array}$ & $\begin{array}{c}21 \\
(1094 \%)\end{array}$ & $\begin{array}{c}14 \\
(10.50 \%)\end{array}$ & $\begin{array}{c}7 \\
(526 \%)\end{array}$ & $\begin{array}{c}11 \\
(8.80 \%)\end{array}$ & $\begin{array}{c}7 \\
(560 \%)\end{array}$ \\
\hline S. typhi in symptomatic & 13 & 19 & 6 & 4 & 10 & 5 \\
\hline \multirow{2}{*}{\multicolumn{7}{|c|}{$\begin{array}{c}\text { patients } \\
\text { Age Group Prevalence (\%) }\end{array}$}} \\
\hline & & & & & & \\
\hline Group & Sym & Asym & Sym & Asym & Sym & Asym \\
\hline $6-17$ & 6 & 1 & 3 & 0 & 4 & 0 \\
\hline $18-29$ & 12 & 2 & 6 & 1 & 4 & 2 \\
\hline $30-41$ & 3 & 2 & 5 & 1 & 3 & 2 \\
\hline $42-53$ & 2 & 1 & 2 & 0 & 2 & 1 \\
\hline $54-65$ & 2 & 0 & 1 & 0 & 2 & 1 \\
\hline $66-77$ & 2 & 0 & 0 & 2 & 1 & 0 \\
\hline Total & 27 & 6 & 17 & 4 & 16 & 6 \\
\hline \multicolumn{7}{|l|}{ Occupational Prevalence (\%) } \\
\hline & \multicolumn{3}{|c|}{ Symptomatic patients } & \multicolumn{3}{|c|}{ Asymptomatic patients } \\
\hline Students & \multirow{2}{*}{\multicolumn{3}{|c|}{$\begin{array}{l}20 \\
10\end{array}$}} & \multirow{2}{*}{\multicolumn{3}{|c|}{$\begin{array}{l}5 \\
6\end{array}$}} \\
\hline Farmers & & & & & & \\
\hline Civil servants & \multicolumn{3}{|c|}{6} & \multicolumn{3}{|c|}{$\begin{array}{l}6 \\
1\end{array}$} \\
\hline Business women & \multicolumn{3}{|c|}{10} & \multicolumn{3}{|c|}{1} \\
\hline House wives & \multicolumn{3}{|c|}{15} & \multicolumn{3}{|c|}{2} \\
\hline \multicolumn{7}{|c|}{ Prevalence of Extended Spectrum $\beta$-lactamase (ESBL) producing Salmonella typhi (\%) } \\
\hline Isolates & \multirow{2}{*}{\multicolumn{3}{|c|}{ Symptomatic patients }} & \multirow{2}{*}{\multicolumn{3}{|c|}{ Asymptomatic patients }} \\
\hline & & & & \multirow{2}{*}{\multicolumn{3}{|c|}{$\begin{array}{c}N=15 \\
1(7.17 \%)\end{array}$}} \\
\hline ESBL producer & \multicolumn{3}{|c|}{$\begin{array}{c}N=61 \\
5(8.19 \%)\end{array}$} & & & \\
\hline Non ESBL producer & \multicolumn{3}{|c|}{$56(91.80 \%)$} & \multicolumn{3}{|c|}{$14(93.33 \%)$} \\
\hline
\end{tabular}

Sym $=$ Symptomatic patients; Asym = Asymptomatic patients

\section{c Antibiogram analysis}

Table 3 summarised the antibiogram profile of the isolates regarded as either ESBL producer or non-EBLS producers. The EBLS producers showed $100 \%$ resistance to ampicillin and ceftrazidime, $83.33 \%$ to ciprofloxacin, while levofloxacin, ofloxacin, and ceftriazone recorded $50 \%$ resistance. Resistance was higher in ESBL-producers than non-ESBL producer as shown in Table 3. Most of the isolates resisted more than three classes of antibiotic. The Multiple Antibiotic Resistance Indices was higher in ESBL-producing isolates than the non ESBL-producers.

Table 3: Antibiogram of non- and ESBL producing Salmonella typhi

\begin{tabular}{ccc}
\hline Antibiotics & $\begin{array}{c}\text { Non-ESBL producer } \\
\mathbf{N}=\mathbf{7 0} \\
\mathbf{n}(\%)\end{array}$ & $\begin{array}{c}\text { ESBL producer } \\
\mathbf{N = 6} \\
\mathbf{n}(\%)\end{array}$ \\
\hline Ofloxacin & $18(28.57 \%)$ & $3(50.00 \%)$ \\
Augmentin & $0(0.00 \%)$ & $0(0.00 \%)$ \\
Ciprofloxacin & $39(55.71 \%)$ & $5(83.33 \%)$ \\
Ampicillin & $70(100 \%)$ & $6(100 \%)$ \\
Ceftianzone & $15(21.43 \%)$ & $5(50.00 \%)$ \\
Imipenem & $70(100 \%)$ & $0(0.00 \%)$ \\
Levofloxacin & $34(48.57 \%)$ & $3(50.00 \%)$ \\
Cefotaxime & $12(17.14 \%)$ & $2(33.33 \%)$ \\
Ceftrazidime & $40(57.14 \%)$ & $6(100 \%)$ \\
\hline
\end{tabular}

$\mathrm{n}=$ number of resistance cases 


\section{DISCUSSION}

Typhoid fever is common in most developing nations of the world due to poor sanitation and lack of access to clean drinking water. The situation have become worse with the emergence of multidrug resistance which makes treatment difficult (Crump and Kirk, 2015). In this study, 450 stool samples were collected and analysed. Of which 75 cases of Salmonella typhi was recorded. The sample were collected from two category of patients. Two hundred and fifty samples were collected from those that have symptoms of the disease (symptomatic), while 200 samples were collected from those that came to the hospital for other complications and did not have symptoms of typhoid fever. The prevalence rate was determined to be 16.18 $\%$ which was lower compared to reports of studies carried out in other parts of the Nigeria. A prevalence of $67.80 \%$ was obtained in a research carried out in Minna by Adogo et al. (2015), 42 \% in Jos by Ukaegbu (2014) and in Kano, Abdullahi et al. (2010) obtained a prevalence of $13 \%$ which was close to the value recorded in this study. Variation noted in the prevalence rate were due to source of water, way of living and level of education. Other reasons are differences in diagnostic methods used, as it has been reported that sensitivity of stool culture is lower compared to blood culture and molecular methods (Ochai, 2010); and the level of awareness which might explain the lower prevalence since about $45 \%$ of those that took part in the research were asymptomatic.

Comparing the prevalence rate of symptomatic and asymptomatic patients of which no statistical significant difference was observed implies that anybody once exposed to high dose of Salmonella typhi could be infected, while manifestation of symptoms depends on other factors (Chatterjee et al., 2012). The prevalence rate of $7.5 \%$ was recorded among the symptomatic patients in this study showing that there were carriers of the disease in the population who will continue to spread the disease without showing symptoms of the disease. This poses a great challenge on the fight against typhoid fever and calls for urgent attention in other to identify such carrier and treat them.

The research work excluded the age group less than five years old because there was no reasonable matched age group for the asymptomatic patience during the research. This was done to avoid bias. Age group $18-29$ presented the highest prevalence. There was a statistical significant differences comparing the age groups and the prevalence obtained $(p<0.05)$. This findings disagreed with the work done in Kaduna by Bobai et al. (2015) who obtained the highest prevalence in children less than 10 years old. Another study designed to check the risk factors of the disease showed that the prevalence was higher in children (Saddiqui et al., 2008). Reasons adduced for high prevalence in the age group $18-29$ in this study may be that high proportion in that class were students who eat what is available as compared to those who boil their water and carefully prepare their own food (Barbara and Sarah., 2011). The challenge of poverty, drought, and scarcity of food in the Northern part of Nigeria also predisposes people to eating anything that is available.

The prevalence of Salmonella typhi was higher among male participants in the study though statistics showed no significant differences between the genders. Findings in this study contrasted report published by Okwonkwo et al. (2010), who obtained higher prevalence in female patients than in male patients. The reason for the higher prevalence observed in male may be that most women stayed home because of religious obligations, while their male counterparts are always outside and are more likely to eat all manner of junks foods. Research have it that one infected cook can infect hundreds of her customer as in the case of Typhoid Mary (Fontana et al., 2003). Unhygienic handling and preparation of food is a key risk factor (Al-Khatib et al., 2004).

Occupation of the patients has effect on the number of Salmonella typhi cases recorded since there was significant statistical difference between them. This implies that the rate of infection depends on the day to day activities of the patients (Crump, 2015). Some occupation tend to have higher risk of exposure than others as reported by Fontana et al. (2003); and the study showed that farmers were predisposed due to life style and level of awareness about the disease (Ram et al., 2008).

Contaminated water is a higher risk factor of the disease in the study area. The odd ratio between the symptomatic and the asymptomatic was above 1 implying that the source of drinking water is an independent risk factor. High odd ratio was also seen among those who have taken antibiotic before $(O R=$ 2.91) meaning that the disease is an independent factor and indiscriminate use of antibiotics is a key risk factor, and is responsible for antibiotic resistance (Barbara and Sarah., 2011).

The study recorded cases of Salmonella typhi among asymptomatic patients $15(7.5 \%)$ which showed the population have a good number of carriers without visible symptoms of typhoid fever making them potential reservoirs. ESBL-producing Salmonella typhi were detected in the study area with the capacity to produce the enzyme beta-lactamase. The prevalence obtained for these resistant isolates agreed with the study carried out in Calabar by Oghenevo et al. (2016) who identified ESBL producer among Salmonella typhi and disagreed with the report of Casmir et al. (2014) who recorded zero prevalence of ESBL-producing $S$. typhi. Salmonell typhi resistance to multiple antibiotics have been documented (Adanbara et al., 2012). This study confirms multiple antibiotics resistance of Salmonella typhi, while ESBL-producing $S$. typhi showed more resistant pattern than non EBLS producers. The ESBL-producing S. typhi with $83.33 \%$ resistance for ciprofloxacin and $100 \%$ to Ceftrazidime and ampicillin agreed with the study of Adanbara et al. (2012).

\section{CONCLUSION}


The study concluded that $S$. typhi prevalence was relatively high from the 3 hospitals where samples were collected and was higher in male than female patients. Isolates with capacity to produce $\beta$ lactamase were obtained which calls for concern since the enzyme confers beta-lactamase resistance factor on bacteria, and can be transferred into other bacterial species. Isolates of Salmonella typhi producing betalactamase presented multi drug resistant pattern to antibiotics tested against them; especially ampicillin, ceftriaxone and ceftraxidime. While discouraging selfmedication, the study implore the government to provide clean and safe drinking water to the people.

\section{REFERENCES}

Abdullahi M (2010). Incidence and antimicrobial susceptibility pattern of Salmonella species in children attending some hospitals in Kano metropolis, Kano State, Nigeria. Bayero Journal of Pure and Applied Science, 3(1): 27-32

Adanbara U, Ezugwu IBU, Momoijimoh A, Madzu A, Hashiimu Z and Damisa D (2012). The prevalence and antibiotics susceptibility pattern of Salmonella typhi among patients attending a military hospital in Minna, Nigeria. Advanced Preventive Medicine, 20 (12): 4-17.

Adogo L, Samuel G and Abalaka M (2015). Sero Prevalence of Salmonella typhi among Pregnant Women in Niger State. Journal of Microbiology Research, 5(3):118-121

Akinyemi KO, Iwalokun BA, Alafe OO, Mudashiru SA and Fakorede C (2015). blaCTX-M-I group extended spectrum beta lactamase-producing Salmonella typhi from hospitalized patients in Lagos, Nigeria. Infection and Drug Resistance, 8: 99-106.

Al-Khatib I, Giacaman R, Husseini A, Ramlawi A, Atiyya I and Salem I (2004). Microbiological quality of food samples from restaurants and sweet shops in developing countries: a case study from the Occupied Palestinian Territory. International Journal of Environmental Health Research; 14: 443-52.

Alocilja EC and Radke SM (2003). Market analysis of biosensors for food safety. Biosensors and Bioelectronics; 18, 841E 846

Barbara ML and Sarah JO (2011). The occurrence and prevention of foodborne disease in vulnerable people. Foodborne pathogens and disease; 8(9): 961-973.

Bobai M, Harriet U and Nandita D (2015). Prevalence of Multidrug Resistant Salmonella enteric Serovar Typhi in Kaduna Metropolis, Kaduna, Nigeria. International Journal of Current Microbiology and Applied Sciences 3(4): 23-33.

Bradford PA (2001) Extended-Spectrum $\beta$-Lactamases in the 21st Century: Characterization, Epidemiology, and Detection of This Important
Resistance Threat. Clin Microbiol Rev., 4(4): 933951.

Cardinale E, Colbachini P, Perrier-Gros-Claude JD, Gassama A and Aıdara-Kane A (2009). Dual emergence in food and humans of a novel multi resistant serotype of Salmonella in Senegal: Salmonella enteric subsp. enterica serotype 35:c:1,2. Journal of Clinical Microbiology; 39: 2373-2374.

Casmir ICl, Bassey EB, Nkiruka FI and Nazek AG (2014). Molecular characterization and antibiotic resistance of Salmonella in children with acute gastroenteritis in Abuja, Nigeria. Journal of Infectious Diseases in Developing Countries; 8(6):712-719.

Catlin BW (1975). lodometric detection of Haemophilus influenzae $\beta$-lactamase: rapid presumptive test for ampicillin resistance. Antimicrobial Agent Chemotherapy; 7:265-270.

Chatterjee M, Chakraborty B, Chatterjee S, Bose M, Mukherjee K, Basu A and Ghosh U (2012). Enteric fever in an HIV/AIDS patient: Atypical manifestations. Iranian Journal of Microbiology, 4(3), 150-152.

Cheesbrough M (2010). District laboratory practice in tropical countries, Part 2, Low Price Edition, Cambridge University Press.

Cheesbrough M (2011). District Laboratory Practice in Tropical Countries Part 1, 2nd edition, Cambridge University Press, New York, pp. 451-621.

Crump JA, Stephen P and Luby ED (2004). The global burden of typhoid fever. Bull Mosby, pp. 367-84.

Crump JA and Kirk MD (2015). Estimating the burden of febrile illness. PLoS Neglected Tropical Diseases, 9(12): e0004040

Fahad JS, Syed RH and Zulfiqar AB (2008). Risk factors for typhoid fever in children in squatter settlements of Karachi: A nested case-control study Volume 1, Issue 2, Pages 113-120

Fontana J, Stout A, Bolstorff B and Timperi R (2003). Automated ribotyping and pulsed-field gel electrophoresis for rapid identification of multidrugresistant Salmonella serotype in Newport. Emergence Infectious Disease; 9, 496-499.

Guibourdenche M, Roggentin P, Mikoleit M, Fields PI, Bockemull J, Grimont PA and Weill FX (2010). Supplement 2003-2007 (No. 47) to the WhiteKauffmannl-lee. Resource of Microbiology; 16, 2629.

Krumperman PH (1983). Multiple antibiotics resistance indexing. Escherichia coli to identify risk sources of faecal contamination of foods. Applied Environmental Microbiology, 46:165-170.

Literacka E, Bedenic B, Baraniak A, Fiett J, Tonkic M, Jajic-Bencic I and Gniadkowski M (2009). blaCTX$\mathrm{M}$ genes in Escherichia coli strains from Croatian hospitals are located in new (blaCTX-M-3a) and widely spread (blaCTX-M-3a, blaCTX-M-15) genetic structures. Antimicrob. Agents Chemother. 53:1630-1635.

Marathe SA, Lahiri A, Negi VD and Chahravortty D (2012). Typhoid fever \& vaccine development: a 
partially answered question. Indian Journal of Medical Resource; 135: 161-169.

Marks F, Kalckreuth V, Aaby P, Adu-Sarkodie Y, et al. (2017). Incidence of invasive Salmonella disease in Sub-Saharan Africa: a multi-centre population based surveillance study. Lancet Global Health, 5: 310-323.

Naseer U, Haldorsen B, Tofteland S, Hegstad K, Scheutz F, Simonsen GS, Sundsfjord A and Norwegian ESBL Study Group (2009). Molecular characterization of CTX-M-15-producing clinical isolates of Escherichia coli reveals the spread of multidrug-resistant ST131 (O25:H4) and ST964 (O102:H6) strains in Norway. APMIS; 117(7):52636.

National Committee for Clinical Laboratory Standard (NCCLS) (2002). Performance Standard for Antimicrobial Disk Susceptibility Testing. Twelfth information supplement science and Education Publishing.

Ochiai RL, Xu ZY, Jodar L and Clemens JD (2010). Trends and disease burden of enteric fever in Guangxi province, China, 1994-2004; Bull World Health Organ, 88(9): 689-96.

Oghenevo O, Bassey B, Yhiler N, Francis $U$ and Angela $O$ (2016). Antibiotic Resistance in Extended Spectrum Beta-Lactamases (ESBLs) Salmonella species isolated from patients with diarrhoea in Calabar, Nigeria. Journal of Clinical Infection Disease Practice; 26 1:15.

Okonko IO, et al. (2010). Prevalence of Salmonella typhi among Patients in Abeokuta, South-western Nigeria. Br J Pharm Toxicol; 1(1): 6-14.
Okonkwo IO, Soleye FA, Adeyi AO and Abubakar MI (2010). Prevalence of Salmonella typhi among patients in Abeokuta, south-western Nigeria. British Journal of Pharmacology and Toxicology. 1(1): 6-14.

Opara AU, Egbuobi RC, Ndudim JN, Onyewuchi CE and Nnodim JK (2014). Antibacterial activity of Ocimum gratissimum (Nchu-Anwu) and Vernonia amygdalina (Bitter-Leaf) antibacterial activity of Ocimum gratissimum (Nchu-Anwu) and Vernonia amygdalina a (Bitter-Leaf). British Biotechnology Journal; 1115-1122.

Parry CM (2006). Epidemiological and clinical aspects of human typhoid fever. In Matroeni, P. and Maskell, D. (Eds.). Salmonella infections: Clinical, immunological and molecular aspects, p. 1-18. New York: Cambridge University Press.

Paul S, Bezbarauh RL, Roy MK and Ghosh AC (1997). Multiple antibiotic resistant index and its reversion in Pseudomonas aeruginosa. Letters of Applied Microbiology, 24: 109-171.

Ram PK, Crump JA, Gupta SK, Miller MA and Mintz ED (2008). Analysis of Data Gaps Pertaining to Shigella Infections in Low and Medium Human Development Index Countries, 1984-2005. Epidemiology and Infection; 136 (5): 577-603

Ranjbar R, Glammanco GM, Aleo A, Plaro MR, Naghomi A, et al. (2010) Resistance threat. Clin Microbiol Rev 14: 933-951.

Ukaegbu CO, Nnachi AU, Mawak JD and Igwe CC (2014). Incidence of Concurrent Malaria and Typhoid Fever Infections in Febrile Patients in Jos, Plateau State Nigeria. International Journal of Scientific \& Technology Research; 3(4), 34-51

Cite this Article: Lamini JN, Nfongeh JF, Orole OO (2018). Extended Beta-Lactamase (ESBL) Producing Salmonella typhi from Presumptive Typhoid Patients in Nasarawa State, Nigeria. Greener Journal of Epidemiology and Public Health, 6(3): 080086, http://doi.org/10.15580/GJEPH.2018.3.050918069. 